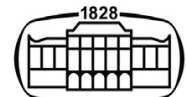

AKADÉMIAI KIADÓ

\title{
Reconstruction place script to awake the general public's memories
}

\author{
Chao Ren $^{1 *}$ and Gabriella Medvegy ${ }^{2}$
}

\section{Pollack Periodica \\ An International Journal \\ for Engineering and Information Sciences}

16 (2021) 3, 164-168

DOI:

$10.1556 / 606.2021 .00360$

(c) 2021 The Author(s)

\section{ORIGINAL RESEARCH}

\section{PAPER}

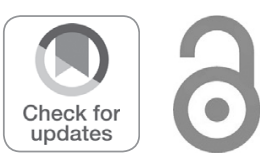

${ }^{1}$ Breuer Marcel Doctoral School, Faculty of Engineering and Information Technology, University of Pécs, H-7624, Pécs, Hungary

${ }^{2}$ Faculty of Engineering and Information Technology, University of Pécs, H-7624, Pécs, Hungary

Received: December 30, 2020 • Revised manuscript received: April 7, 2021 • Accepted: April 20, 2021

Published online: May 26, 2021

\section{KEYWORDS}

place script, place making, general public's memories, landscape architecture design

\section{INTRODUCTION}

With the rapid development of society, urban construction is facing the crisis of tending to the same shape. Megacities are universalized, mechanized, and standardized, and they have completely lost their humanity. This is a signal that cities are going to die [1]. Especially in China, urban construction needs to pay attention to Chinese culture and respect the original characteristics of the city, instead of making all the cities like Manhattan. China's urban construction needs to take into account the characteristics of regional culture. At present in China, art is actively involved in rural construction by various forms with a vigorous momentum [2].

Architecture and landscape architecture have always provided not only the public space for people to live but also the material carrier of the public's memories. In particular, there were some public spaces that were closely related to people's lives, which constantly created the public's emotions and memories. However, in the process of rapid expansion of Chinese cities and towns in recent years, the urban cultural heritage lacks definition and theoretical research as support and has not formed a reasonable evaluation system and protection mechanism. These precious places have not received corresponding information in urban renewal. Pay attention to that many cultural spaces, memory spaces, and emotional spaces have been demolished and rebuilt or faced the fate of being demolished at any time.

\section{MATERIALS AND METHODS}

By combining theoretical research and case study methods, the author applies the research results of regional culture and landscape architecture design theories and the creative 
methods summarized into practical design projects, study the problems in practice, and looks for practical design methods.

\section{PLACE SCRIPT}

\subsection{What is a place script?}

Re-construction place script refers to planning and arranging urban stories in place spaces according to the principles of architecture, organically organizing people's daily behaviors and urban contexts, influencing the generation of space, and shaping the spatial image of landscape architecture. And can use the scripted space to influence people's living habits and ideas.

Place script is the deconstruction and reorganization of the relationship between function and form in urban design, guiding the public to interact with the place space and inheriting the urban context. In the existing landscape architecture design experience, the strategy of the script is to tell the story of the soon-to-be-forgotten urban context through spatial design through orderly arrangement or montage, and other means in the site space, or some cultural values can be arranged into places through piecemeal design. This paper argues that the word "place" contains two levels of meaning, one is the material level, the other is the cultural level, and the former covers the physical location, physical entity, spatial organization. The latter includes people's understanding of local emotions, perceptions, meanings, symbols, the relationship between people and space, as well as the formation process of the relationship. The place is not only a pure physical space, but also carries the history, experience, emotion, meaning and symbol of people's cognitive space. The latter, to a certain extent, can be expressed through physical entities, but it comes more from diverse urban activities.

Place script to build public environment as a whole is a kind of design method, it integrates the culture, stories, ethics, history, economy, society, population and environment problems, actively cultivate and interactive relationship between environment, through the use of urban design, architectural design and landscape design to create a specific field, enrich the public environment, to promote community, government, developers, planners, architects, artists, its goal is to adapt to the specific site of society, economy, history, environment and culture to enhance and develop a unique community recognition.

The core of the site script is to create a lasting value of the public life space by cultivating the urban public space culture and creating a sense of place. In the past 20 or 30 years, cities in Europe and America are more and more inclined to adopt the strategy of site-building to improve and improve the quality of the urban environment and have achieved great success. Comparatively speaking, European countries tend to use the strategy of the site created to promote the revival of old urban areas, while North American countries mainly use it to transform the site-free environment caused by suburban sprawl. Therefore, the site construction covers public space, old town renewal, historical location, community, and other aspects.

\subsection{Characteristics of place script}

On the subjective side, it mainly describes human behavior and the process of event generation. Human behavior events in space, it is a dynamic process from the body's multi-level motivation needs to people's perception of space so that behavior events occur in the space. On the objectively side, the space form, material, light, and shadow of the space place play a crucial role in the presetting of the event. Based on the generation of preset events, the generation of physical space is promoted and controlled mainly through the strategy of preset events and the mechanism of spatial generation.

\subsection{General public's memories}

The regional landscape architecture design is a complex unity of science that integrates the living habits, culture, art, and natural conditions of the residents. Culture is regional, and regional culture is the result of generations of creation and evolution of people living in a specific living environment and historical conditions. Landscape architecture design should consider regional culture, which may also become a landmark landscape the region, may also affect people's lifestyles, and become the emotional destination of the public, and become part of the collective memory of the public. From an aesthetic point of view, nostalgia is a unique aesthetic psychology, a value discrimination and imaginary structure based on memories, and an imaginary cultural memory [3].

The memory of the city is not just a mere intangible existence, but also not only the old streets and alleys of the "old and dying years". It can be a well-preserved, magnificent and magnificent ancient building, or an authentic dialect, sometimes even just some symbols and colors can bring people into the history of a city for thousands of years. The image of the city is contained in tangible objects. It is possible for any observer to evoke the characteristics of a strong image. There are differences and connections in the urban environment, and the observer uses powerful adaptation. Ability to choose, organize and give meaning to what you see according to your own wishes [4].

The design of urban landscape architecture should not only consider the material needs, but also satisfy the inheritance or reproduction of city memory. Losing the memory of its origin and the principle of continuity, the city will be on the verge of destruction [5]. The design of urban landscape architecture should pay attention to the representation of the form of the general public's memories to some extent. For the excavation of the general public's memories, various factors in the design site need to be analyzed, sorted out, historical culture is explored to form design elements, ultimately achieve the continuation and inheritance of regional culture. 


\section{A CASE STUDY}

\subsection{Summary of the renovation project of Jingdezhen ceramic street}

Jingdezhen is one of the most important cities in the field of ceramic creation and production in the world. It has a history of more than two thousand years of smelting and is an important cultural carrying place in China. In the modern development of Jingdezhen, many blocks have aged and become unsuitable for residents' lives. Modern comfortable life is the dream of villagers and they consider the renewal of their villages to be the most convenient option to achieve modern living standards [6]. This time, the project chose a decaying street near a 40 -year-old pottery factory and a warehouse, all of which were in ruins as it is shown in Fig. 1. The project is located on a dilapidated street near a 40 -yearold pottery factory and warehouse, all of which were in ruins as it is shown in Fig. 2. There is also a garbage dump going in, it smells bad. Children from the surrounding area play here because it is far from the main street and relatively private. Moving inward, there is also a garbage dump, which smells very bad. Children around are playing here because it is far away from the main street and relatively private as it is shown in Fig. 3.

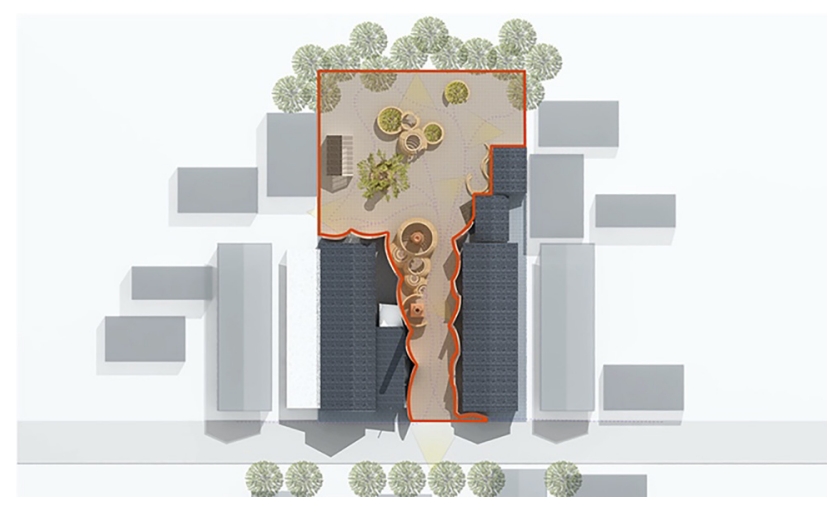

Fig. 1. The range of design (Source: author's drawing)

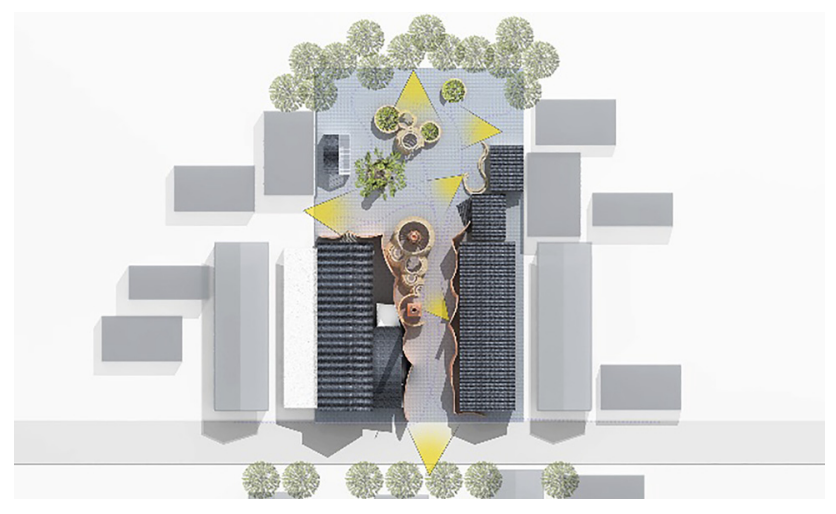

Fig. 2. The extent of people's vision (Source: author's drawing)

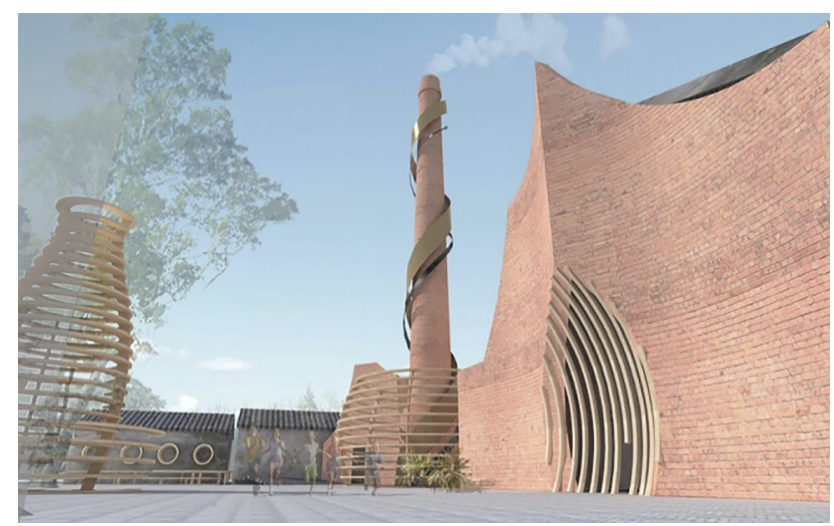

Fig. 3. Entertainment and leisure space (Source: author's drawing)

The design introduces the traditional cultural symbols of ceramics and brings a high-quality entertainment and leisure environment to the children in this neighborhood. Traditional symbol is an effective and no negligible material of creating attractive form [7], while having fun here; the children can also experience Jingdezhen's ceramic culture and participate in environmental protection as it is shown in Figs 4 and 5.

\subsection{Place script and space}

The location of this project is a small branch road of Jingdezhen Ceramic Street, which is a pocket space extending from the main road to the living area. The entrance is a relatively narrow path inside, and people will see a small empty space halfway through. This design also relies on the scenario script, hoping that the visitors can feel the uniqueness of the space in the entrance. The script for space from the entrance to the interior is set to a linear layout. Visitors will gradually experience the ceramic culture from the perspective of spatial arrangement.

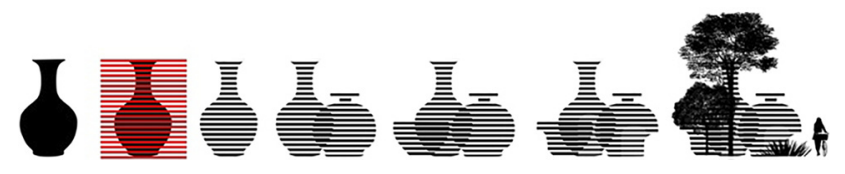

Fig. 4. The design idea was derived from the vessels produced in the area

(Source: author's drawing)

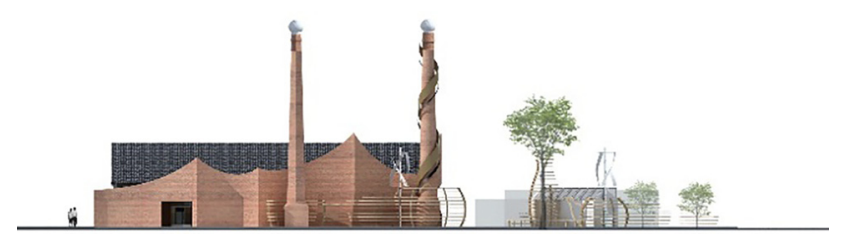

Fig. 5. The relationship between the design and the original building

(Source: author's drawing) 


\subsection{Place script and form}

The design of different parts of the site is also carefully arranged according to the needs of the site script. The high walls on both sides of the entrance have a sense of space envelopment. The rectangular ceramic bricks made of clay quickly immerse visitors in the ceramic culture. $15 \mathrm{~m}$ away from the entrance is the old chimney of the tall ceramic factory. The design combines the shape of ceramic ware to carry out the superposition reconstruction and designs an experience space combining the chimney and ceramic ware as it is shown in Fig. 6. After that, the core part of the whole space is the leisure space and entertainment space influenced by the design of various ceramic forms. The whole design arrangement will be in the form of the use of echoes and site scrip.

\subsection{Place script and nature}

Located near 30 degrees north latitude, Jingdezhen has a subtropical monsoon climate with abundant climate changes, dense vegetation, clouds, rain, stars, and sunshine. There are many designs that incorporate natural wind and rain vegetation. For example, in the design of the function of the vent, a large grating round hole is opened on the wall extending from the entrance like the back courtyard. The round hole is like a part of a round vessel. This hole can share the phenomenon that local airflow tends to overflow in the pocket space, and also enrich the airflow experience in the local space. The design of the sunshine room is simple and easy to use. The daylight enters into the internal space, which can be used as a functional room of the area. The design of combining trees with landscape makes the entertainment space of ceramic ware more vibrant. There are also pneumatic devices that generate electricity for space. In this way the arrangement of field script is to make people live in harmony with nature and educate people to live in harmony with nature.

\subsection{Site script and materials}

The city of Jingdezhen is also world-renowned in the use of materials, so the design hopes that the materials used in the

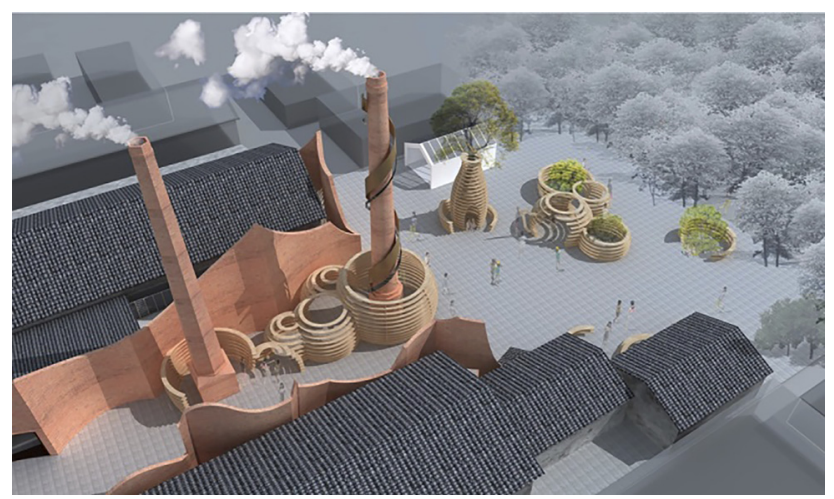

Fig. 6. The experience space combining the chimney and ceramic ware

(Source: author's drawing) design of the field script can reflect the texture of the city. It increases dependence on the local natural resources and passive strategies to provide a stable comfortable environment, while using simple construction methods [8]. The curtain walls on both sides of the entrance are made of fired adobe, and when people get close to touching the ceramic civilization of thousands of years. The small landscape in the form of utensils is made of anticorrosive wood, and the shape of the utensils is more meaningful. Since ancient times, ceramics are mostly made of wood, and the shape of the utensils is produced in the wood fire as it is shown in Fig. 7. In addition, it also includes living trees, black bricks, metal, tiles, and other traditional materials to enrich the experience of field script.

\subsection{Place script and participation}

Field scripting can also be created through participation. Participation is more likely to stimulate the perception of different people. In the reconstruction of old street, the design added the manual pneumatic device, which can generate electricity or drive the pneumatic device to help the airflow in local space when there is no wind. The experience of rotating is the same as that of casting porcelain. Besides, there are lot of leisure spaces that require people to sit directly in the interior of some huge ceramic vessels for leisure. At the same time, people seem to be objects in the vessels. At this time, people seem to participate in the setting of the scene as objects.

Landscape design from the perspective of experience emphasizes the shaping of different experience scenes and the leading role of experiencers in the landscape as it is shown in Fig. 8. Centering on the landscape generated by experience, the subjectivity of human beings is put in the first place so that the shaping and organization of landscape elements are centered on human feelings and rules of activities, and the influence of rigid form and vandalism on the sustainable development of landscape is avoided.

\subsection{Place script and time}

Time and space, nature, behavior, materials, and many other things affect each other. When the field script is designed the

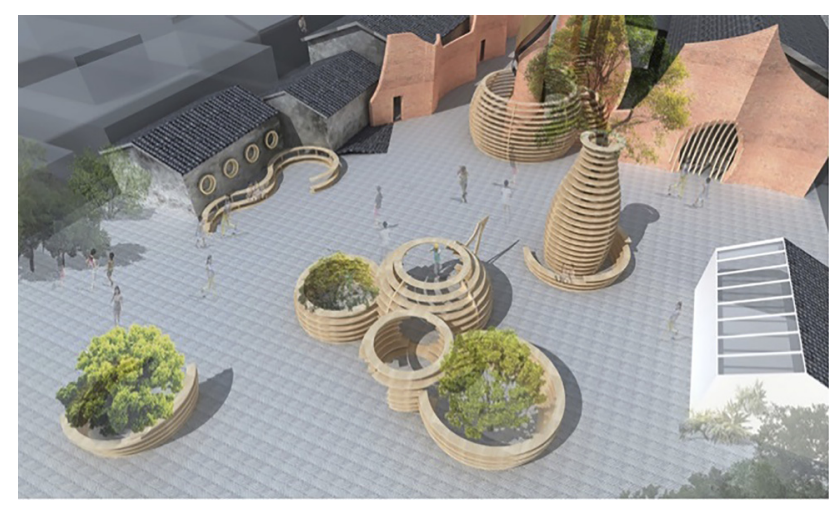

Fig. 7. The space of the shape of the utensils (Source: author's drawing) 


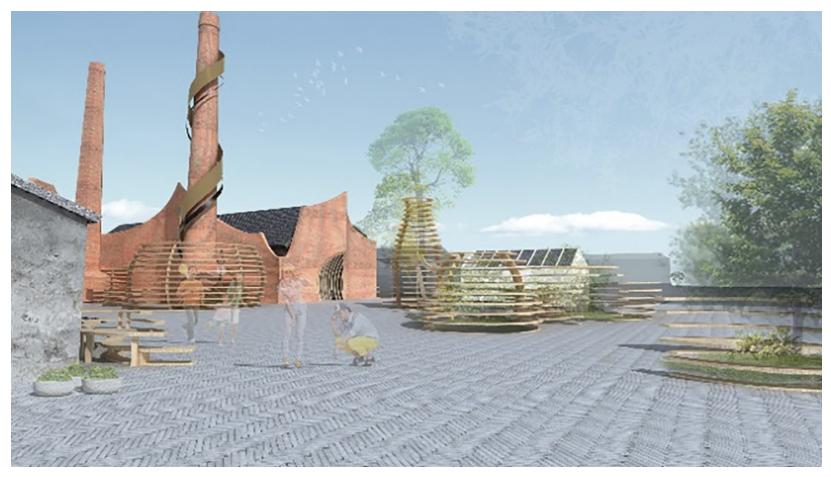

Fig. 8. The perspective of experience (Source: author's drawing)

designer hopes to use the change of time to influence the experience of space. For example, a series of different effects, in the change of the sun's rays from morning to night, in the change of cold and warmth of wind and rain in different seasons, in the change of the oxidation of materials in different degrees designers need to be considered and used all these in advance.

\section{CONCLUSION}

The site script focuses on the public domain of the city and should help people to fully understand the city spirit and city culture. In a good script, arrange the field with more details that you cannot see but can experience. An attractive and unique urban place is not only from the features of form but also from the safety, comfort, enlightenment, sustainability, cultural characteristics, and other aspects of the environment. To create a place for people is fundamental to create a life for people and provide a high-quality urban environment for the public. The study of site script can provide the core concept for urban development in the process of highspeed urbanization, and make urban construction transform from quantitative change to qualitative change.

\section{REFERENCES}

[1] L. Mumford, The City in History: Its Origins, its Transformations, and its Prospects. New York: Harcourt, Brace and Company, 1961.

[2] Y. Shi, A. M. Tamás, and G. Sztranyák, "Restoring rural landscape: A case study in Chongqing China," Pollack Period., vol. 15, no. 3 , pp. 232-242, 2020.

[3] J. J. Zhao, "Imaginary cultural memory, on the aesthetic psychology of nostalgia" (in Chinese), Shanxi Normal Univ. J., vol. 32, no. 2, pp. 54-57, 2005.

[4] K. Lynch, The Image of the City. Cambridge, MA: MIT Press, 1960.

[5] M. C. Boyer, The City of Collective Memory, its Historical Imagery and Architectural Entertainments. Cambridge, MA: MIT Press, 1994.

[6] D. Zhao, B. Bachmann, and T. Wang, “Beautiful China' project: A development proposal for non-heritage rural areas in North China," Pollack Period., vol. 14, no. 1, pp. 235-246, 2019.

[7] Q. Zhang and A. Hutter, "From traditional symbol to new contemporary form," Pollack Period., vol. 14, no. 3, pp. 3-10, 2019.

[8] A. A. Khalil, M. Fikry, and W. Abdeaal, "High technology or low technology for buildings envelopes in residential buildings in Egypt," Alexandria Eng. J., vol. 57, no. 4, pp. 3779-3792, 2018. 